\title{
Selection criteria related to long-term survival following liver transplantation for colorectal liver metastasis
}

\author{
Svein Dueland $^{1}(\mathbb{D})$ | Harald Grut ${ }^{1,2}$ (D) | Trygve Syversveen ${ }^{2}$ | Morten Hagness ${ }^{1,3}$ | \\ Pål-Dag Line L $^{1,3,4}$
}

${ }^{1}$ Experimental Transplantation and Malignancy Research Group, Division of Surgery, Inflammatory Diseases and Transplantation, Oslo University Hospital, Oslo, Norway

${ }^{2}$ Department of Radiology and Nuclear Medicine, Oslo University Hospital, Oslo, Norway

${ }^{3}$ Section for Transplantation Surgery, Department of Transplantation Medicine, Oslo University Hospital, Oslo, Norway

${ }^{4}$ Institute of Clinical Medicine, University of Oslo, Oslo, Norway

\section{Correspondence}

Svein Dueland

Email: svedue@ous-hf.no

\section{Funding information}

The study was supported by Oslo University Hospital, the Norwegian Cancer Society, and South-Eastern Norway Regional Health Authority.

\begin{abstract}
Patients with nonresectable colorectal cancer receiving palliative chemotherapy have a 5 -year overall survival rate of about $10 \%$. Liver transplant provided a KaplanMeier-estimated 5-year overall survival of up to $83 \%$. The objective of the study was to evaluate the ability of different scoring systems to predict long-term overall survival after liver transplant. Patients with colorectal cancer with nonresectable liveronly metastases determined by computed tomography (CT)/magnetic resonance imaging/positron emission tomography (PET)-CT scans from 2 prospective studies (SECA-I and -II) were included. All included patients had previously received chemotherapy. PET-CT was performed within 90 days of the liver transplant. Overall survival, disease-free survival, and survival after relapse based on the Fong Clinical Risk Score, total PET liver uptake (metabolic tumor volume), and Oslo Score were compared. At median follow-up of 85 months for live patients, Kaplan-Meier overall survival rates at 5 years were 100\%, 78\%, and 67\% in patients with Fong Clinical Risk Score 0 to 2, metabolic tumor volume-low group, and Oslo Score 0 to 2, respectively. Median overall survival was 101, 68, and 65 months in patients with Fong Clinical Risk Score 0 to 2, metabolic tumor volume-low, and Oslo Score 0 to 2. These selection criteria may be used to obtain 5-year overall survival rates comparable to other indications for liver transplant.
\end{abstract}

\section{KEYWORDS}

cancer/malignancy/neoplasia, cancer/malignancy/neoplasia: metastatic disease, clinical research/practice, clinical trial, liver disease: malignant, liver transplantation/hepatology

\section{1 | INTRODUCTION}

Colorectal cancer (CRC) is the third most common malignancy worldwide. ${ }^{1}$ About half of the patients have metastases at time of 
metachronous disease (metastatic disease detected $>12$ months from diagnosis), $>1$ liver lesion, size of largest liver metastases of $\geq 5 \mathrm{~cm}$, carcinoembryonic antigen (CEA) levels $>200 \mu \mathrm{g} / \mathrm{L}$, and lymph node-positive primary colorectal tumor (Fong Clinical Risk Score $[\text { FCRS }]^{2}$ ). About $20 \%$ of the patients with CRLMs are candidates for liver resections, ${ }^{3}$ but about $60 \%$ to $70 \%$ have recurrence within 3 years. ${ }^{4}$ Palliative chemotherapy is therefore the treatment option for the majority of patients with CRLMs. The median OS from start of first-line chemotherapy is about 2 years and 5 -year OS is about $10 \%$, although longer median OS has been obtained in selected patients with good performance status (ECOG 0 or 1), no (K)RAS or BRAF mutations, and left-sided tumors. ${ }^{5-9}$

Liver transplant (LT) is the standard of care for selected patients with malignant liver tumors such as hepatocellular carcinoma (HCC) and liver metastases from low-grade neuroendocrine tumors. ${ }^{10,11}$ In the 1990s, LT in patients with CRC was abandoned because of a 5 -year OS of $<20 \% .{ }^{12}$ In 2006, we started a pilot study (SECA-I) reexamining LT in patients with CRC with nonresectable liver-only metastases. The results in 21 cases were reported in 2013 when the first included patient had been observed for 5 years and the estimated 5 -year OS was $60 \% .^{13}$ Pretransplant maximal tumor diameter $>5.5 \mathrm{~cm}$, level of CEA before $\mathrm{LT}>80 \mu \mathrm{g} / \mathrm{L}$, failing response on chemotherapy, and an interval from resection of the primary tumor to transplant of $<2$ years were all factors associated with decreased survival. We used ${ }^{18} \mathrm{~F}$-fluorodeoxyglucose positron emission tomography $\left({ }^{18} \mathrm{~F}\right.$-FDG $\mathrm{PET}$ ) in combination with computed tomography (CT) to exclude extrahepatic metastases; further, patients with high liver PET uptake had reduced 5-year OS after LT. ${ }^{14}$ We showed elsewhere that patients with response to chemotherapy, lower CEA levels at time of LT, and smaller and fewer liver metastases have a Kaplan-Meier (KM)-estimated 5 -year OS of $83 \% .{ }^{15}$

The aim of the present study was to investigate how 3 different clinical scoring systems could predict long-term survival after LT of patients with CRC with nonresectable liver only metastases.

\section{2 | METHODS}

This report is based on 2 prospective clinical trials that included patients with nonresectable CRC liver-only metastases (Clinical Trials. gov NCT01311453, SECA-I; Clinical Trials.gov NCT01479608, SECA-II). The SECA-I study included 23 patients from November 2006 to April 2012; the SECA-II study started in April 2012 and is ongoing. To standardize the pretransplant PET/CT evaluation and avoid underestimation of possible disease progression in cases with a long interval between PET/CT and transplant, only patients having a PET/CT scan within 90 days of LT were included. Nineteen patients (14 and 5 patients from the SECA-I and SECA-II trails, respectively) met these inclusion criteria. The end of follow-up was March 3, 2019. Both studies were approved by the regional ethics committee and institutional review board. The inclusion and exclusion criteria have been reported previously. ${ }^{13}$ The main inclusion criteria were nonresectable liver-only disease determined by a multidisciplinary liver meeting with HPB surgeons, liver transplant surgeons, radiologists, and oncologist; no extrahepatic disease determined by $\mathrm{CT}$ and PET/CT scans; previous chemotherapy; and good performance status (ECOG 0 or 1). Some of the included patients had previously had liver resection. The criteria for resectable disease vary between surgeons and institutions, and there was a development during the study period. The immunosuppression protocol consisted of induction with basiliximab, sirolimus (mTOR inhibitor), or tacrolimus the first 4 to 6 weeks and then conversion to sirolimus (SECA-II study). ${ }^{15}$ Glucocorticoids and mycophenolate mofetil were administered from day 0 ; steroids were tapered to 0 during the first 3 to 6 months. None of the patients received adjuvant chemotherapy after LT.

Patients had follow-up every month during the first year, every 3 months during the second year, and every 6 months thereafter for up to 10 years. CT scans were performed every 3 months during the first 2 years and then every 6 months. Follow-up and treatment at time of relapse were at the discretion of the responsible physician.

Disease-free survival (DFS) was defined as time from LT to suspected metastatic lesions or local relapse described by $\mathrm{CT} /$ magnetic resonance imaging/PET-CT scans, occurrence of new CRC primary, or diagnosis of other malignant disease. OS was calculated from date of LT to the end of follow-up. OS from time of relapse was calculated as OS minus DFS.

From the pretransplant ${ }^{18} \mathrm{~F}$-FDG PET/CT examination, metabolic tumor volume (MTV) was measured and calculated for all liver metastases. ${ }^{14} \mathrm{MTV}\left(\mathrm{cm}^{3}\right)$ was defined as the tumor volume with ${ }^{18}$ F-FDG uptake segmented by a fixed threshold of $40 \%$ of the maximum standardized uptake value in the volume of interest. Total MTV was calculated by adding the values from all metastases for each patient. Liver background was measured by placing a region of interest of $3 \mathrm{~cm}$ in the right liver lobe. If the metastases were not visible compared with the liver background, an MTV value of 0 was given.

Tumor location from the cecum to the transverse colon was defined as right-sided primary. Risk stratification of the candidates was done by means of the FCRS and the Oslo Score. In FCRS, 0 to 5 points were calculated, giving 1 point for each of the following: synchronous metastatic disease ( $<12$ months from diagnosis), lymph node-positive primary, $>1$ lesion, size $>5 \mathrm{~cm}$, and CEA $>200 \mu \mathrm{g} / \mathrm{L}^{2}$ The Oslo Score ( 0 to 4 points) was calculated by giving 1 point for each of the following pretransplant characteristics: largest lesion $>5.5 \mathrm{~cm}$, plasma CEA levels $>80 \mu \mathrm{g} / \mathrm{L}$, time from surgery of primary tumor to LT of $<2$ years, and progressive disease on chemotherapy at time of $\mathrm{LT}^{13}$

\section{1 | Statistical analyses}

OS and DFS were estimated by using the KM method. Log-rank test was used to compare outcome between groups. Difference between 
groups was compared by Mann-Whitney $U$ test. A 2-tailed probability level <.05 was considered statistically significant. Analyses were performed with SPSS version 25 (IBM, Armonk, NY).

\section{3 | RESULTS}

The baseline characteristics of the 19 patients are given in Table 1. Three of the patients had metachronous liver metastases. Sixteen had (y)pT3 primary tumor, with (y)pN + in 10 patients. Ten patients had MTV $<70 \mathrm{~cm}^{3}$. The median follow-up of patients alive at the cut-off date of this report is 85 months.

Patients with MTV $<70 \mathrm{~cm}^{3}$ (low MTV) had significantly lower median number $(P=.022)$ and size $(P=.002)$ of liver metastases compared with patients with MTV $>70 \mathrm{~cm}^{3}$ (high MTV, Table 2). Patients with low MTV also had significantly lower median CEA levels, FCRS, and Oslo Score compared with patients with high MTV, with $P$ values of .001, .001, and .004, respectively. There was no significant difference between the MTV groups in sex, T stage, $\mathrm{N}$ stage, KRAS mutated patients, right- vs left-sided primary tumor, or time from primary surgery to LT (Table 2 ).

The 9 patients with MTV $>70 \mathrm{~cm}^{3}$ were observed until death. They had a median OS of 27 months from transplant (range 6-86 months). Eight of the 10 patients with MTV $<70 \mathrm{~cm}^{3}$ are alive 33 to 147 months after LT, and 7 have been observed for $>5$ years. Two patients died after 33 and 57 months, respectively. Patients with MTV $<70 \mathrm{~cm}^{3}$ had significant longer DFS, OS, and OS from time of relapse compared with patients with MTV $>70 \mathrm{~cm}^{3}$ (Figure 1AC). Median DFS was 23.0 and 3.5 months in the low- and high-MTV groups, respectively $(P<.001)$, and 5 -year OS was $78 \%$ and $22 \%$, respectively $(P=.001)$. Five-year OS from time of relapse was $71 \%$ vs $11 \%$ in the low- and high-MTV groups, respectively $(P=.014)$.

Six patients had an FCRS of 0 to 2, and 13 patients had an FCRS of 3 to 5. Patients with an FCRS of 0 to 2 had significantly longer DFS, OS, and OS after relapse compared with patients with a score of 3 to 5 (Figure 2A-C). Median DFS in patients with an FCRS of 0 to 2 and 3 to 5 was 23 and 6 months, respectively $(P=.023)$. Two patients with FCRS of 0 to 2 have been observed for 55 and 71 months without signs of relapse. In contrast, all 13 patients with an FRCS of 3 to 5 had a relapse within 47 months. All 6 patients with FCRS of 0 to 2 were alive 33 to 147 months after LT, whereas 5-year OS in patients with an FRCS of 3 to 5 was $31 \%(P=.004)$, with 2 patients still alive after 65 and 98 months after LT (Figure 2B). No patient with an FRCS of 5 survived for 5 years. Four patients with an FRCS of 0 to 2 had recurrence. They are all alive 15 to 115 months after relapse, whereas 5-year OS from time of relapse in patients with an FRCS of 3 to 5 was $15 \%$ with 2 of the 13 patients alive 51 and 59 months after relapse ( $P=.010$, Figure $2 \mathrm{C})$.

Thirteen patients had an Oslo Score of 0 to 2 and 6 patients had an Oslo Score of 3 to 4. Patients with an Oslo Score of 0 to 2 had significantly longer DFS, OS, and OS after relapse compared with patients with score of 3 to 4 , with $P$ values of .004, .004, and .019, respectively (Figure $3 \mathrm{~A}-\mathrm{C}$ ). Median DFS in patients with an Oslo
TABLE 1 Baseline characteristics and previous treatments $(N=19)$

\begin{tabular}{|c|c|}
\hline Age at LT (median, range) & $\begin{array}{l}56.8 \\
(28.7-71.1) y\end{array}$ \\
\hline Sex (female/male) & $8 / 11$ \\
\hline \multicolumn{2}{|l|}{ Treatment before resection of primary } \\
\hline No treatment & 12 \\
\hline Chemotherapy & 3 \\
\hline Chemoradiation therapy & 3 \\
\hline Chemotherapy + radiation therapy & 1 \\
\hline \multicolumn{2}{|l|}{ Primary } \\
\hline урто & 2 \\
\hline (у)рт2 & 1 \\
\hline (у)рт3 & 16 \\
\hline (y)pNO & 9 \\
\hline (y)pN1 & 4 \\
\hline ypN2 & 6 \\
\hline \multicolumn{2}{|l|}{ Location of primary } \\
\hline Right colon & 4 \\
\hline Colon transversum & 1 \\
\hline Left colon & 2 \\
\hline Sigmoid & 4 \\
\hline Rectum & 8 \\
\hline \multicolumn{2}{|l|}{ Chemotherapy before LT } \\
\hline First line & 7 \\
\hline Second line & 9 \\
\hline Third line & 3 \\
\hline \multicolumn{2}{|l|}{ Chemotherapy given before LT } \\
\hline 5-Fluorouracil & 19 \\
\hline Irinotecan & 16 \\
\hline Oxaliplatin & 15 \\
\hline EGFR antibody & 4 \\
\hline Bevacizumab & 7 \\
\hline \multicolumn{2}{|l|}{ At time of LT } \\
\hline KRAS mutation/wt/unknown & $5 / 13 / 1$ \\
\hline CEA at $\mathrm{LT}(\mu \mathrm{g} / \mathrm{L}$, median and range) & $5(1-2002)$ \\
\hline FCRS at LT (median and range) & $3(1-5)$ \\
\hline Median number of lesions on CT scan at LT (range) & $7(1-53)$ \\
\hline Median size of lesions on CT scan at LT (range) & $\begin{array}{l}45 \mathrm{~mm} \\
(7-130 \mathrm{~mm})\end{array}$ \\
\hline Time from diagnosis to LT (median and range) & $\begin{array}{l}24.0 \mathrm{mo} \\
(5.8-78.1 \mathrm{mo})\end{array}$ \\
\hline
\end{tabular}

Time from primary surgery to LT (median and range) $22.3 \mathrm{mo}$

(2.3-78.1 mo)

CEA, carcinoembryonic antigen; CT, computed tomography; EGFR, epidermal growth factor receptor; FCRS, Fong Clinical Risk Score; LT, liver transplant.

Score of 0 to 2 was 19 months, compared with only 3 months in patients with an Oslo Score of 3 to 4 . All patients with an Oslo Score of 3 to 4 had a relapse, whereas 2 patients with an Oslo Score of 0 
TABLE 2 Different parameters between MTV $<70 \mathrm{~cm}^{3}$ and MTV > 70 $\mathrm{cm}^{3}$ groups at time of transplant (median and range)

\begin{tabular}{|c|c|c|c|}
\hline & $M T V<70 \mathrm{~cm}^{3}(\mathrm{n}=10)$ & MTV $>70 \mathrm{~cm}^{3}(\mathrm{n}=9)$ & $P$ value \\
\hline $\begin{array}{l}\text { Time from primary sur- } \\
\text { gery to LT (mo) }\end{array}$ & $14(2-78)$ & $23(6-36)$ & .905 \\
\hline Age, y & $59(53-71)$ & $54(29-60)$ & .028 \\
\hline Sex (female/male) & $4 / 6$ & $4 / 5$ & .905 \\
\hline FCRS at LT & $2(1-4)$ & $4(3-5)$ & .001 \\
\hline Oslo Score at LT & $1(0-2)$ & $3(0-4)$ & .004 \\
\hline No. of lesions & $5(1-36)$ & $22(4-53)$ & .022 \\
\hline Size of lesions (mm) & $30(7-52)$ & $96(26-130)$ & .002 \\
\hline CEA $(\mu \mathrm{g} / \mathrm{L})$ & $2(1-30)$ & $274(3-2002)$ & .001 \\
\hline KRAS (wt/mutant) & $2 / 7$ & $3 / 6$ & .730 \\
\hline (y)pT-stage & $\mathrm{T} 2=1, \mathrm{~T} 3=9$ & $\mathrm{TO}=2, \mathrm{~T} 3=7$ & .604 \\
\hline (y)pN-stage & $\mathrm{NO}=7, \mathrm{~N} 2=3$ & $\mathrm{NO}=2, \mathrm{~N} 1=4, \mathrm{~N} 2=3$ & .079 \\
\hline Right- vs left-sided & $1 / 9$ & $3 / 6$ & .400 \\
\hline
\end{tabular}

CEA, carcinoembryonic antigen; FCRS, Fong Clinical Risk Score; LT, liver transplant; MTV; metabolic tumor volume.

${ }^{a}$ Nonparametric Mann-Whitney $\mathrm{U}$ test.
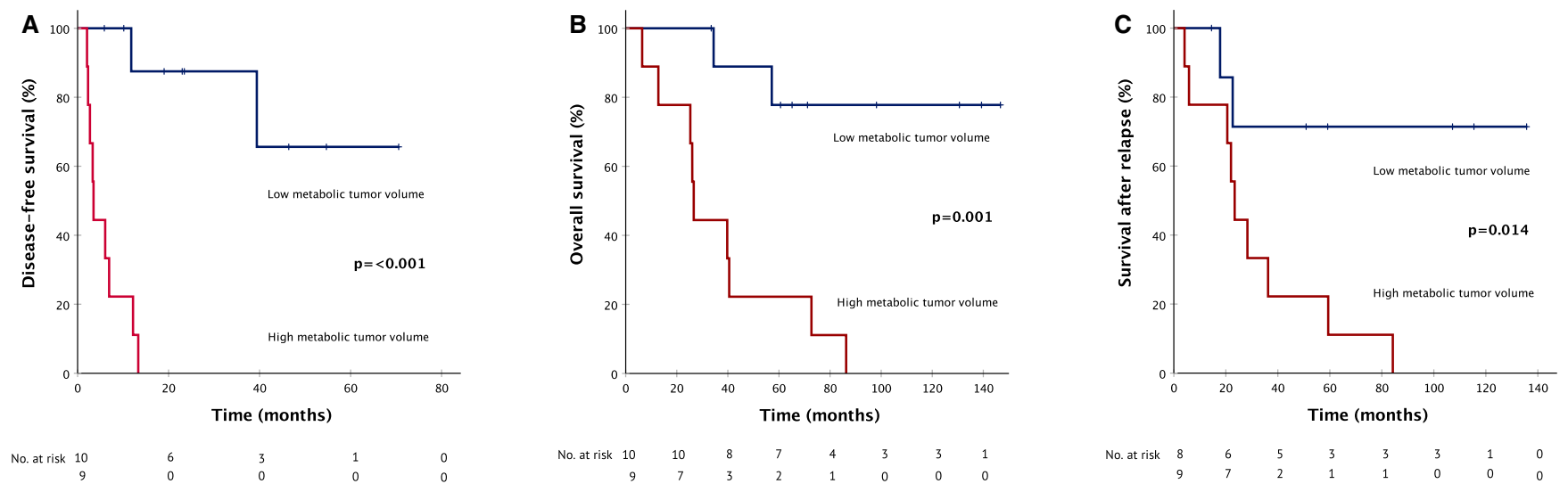

FIGURE 1 Disease-free survival (A), overall survival (B), and survival after relapse (C), from time of liver transplant in patients with colorectal cancer with nonresectable liver-only metastases receiving liver transplant. Metabolic tumor volume (MTV) in liver determined by PET scans. Blue line, MTV $<70 \mathrm{~cm}^{3}$; red line, MTV $>70 \mathrm{~cm}^{3}$ [Color figure can be viewed at wileyonlinelibrary.com]
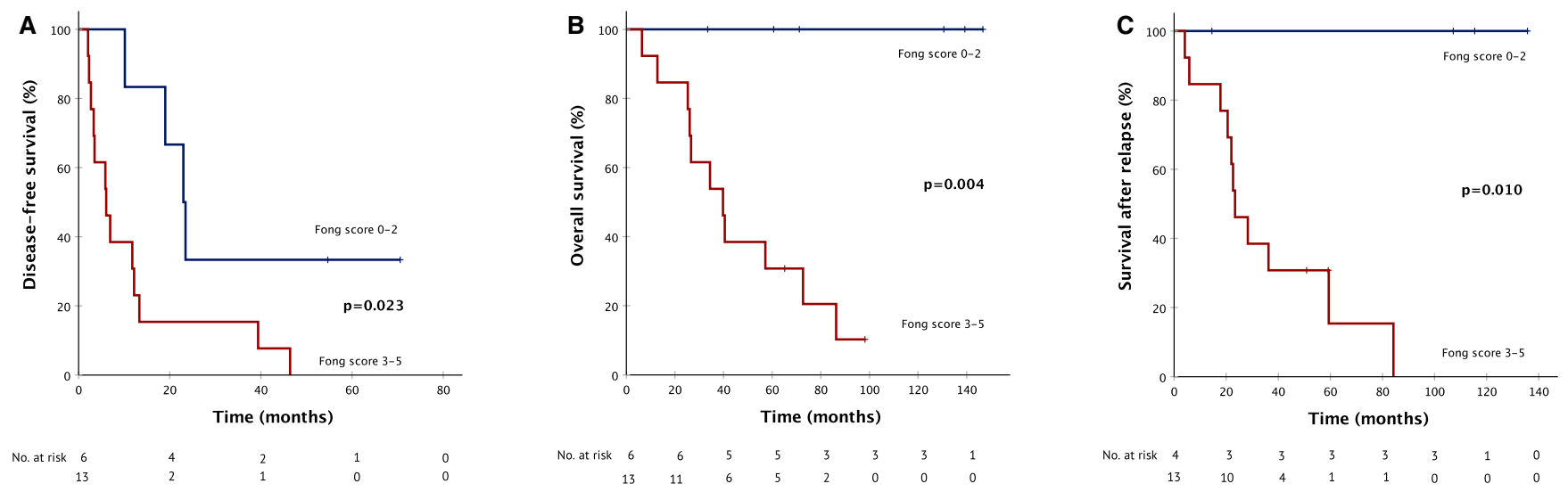
FIGURE 2 Disease-free survival (A), overall survival (B), and survival after relapse (C), from time of liver transplant in patients with
colorectal cancer with nonresectable liver-only metastases receiving liver transplant. Blue line, Fong Clinical Risk Score 0 to 2; red line, Fong Clinical Risk Score 3 to 5 [Color figure can be viewed at wileyonlinelibrary.com] 

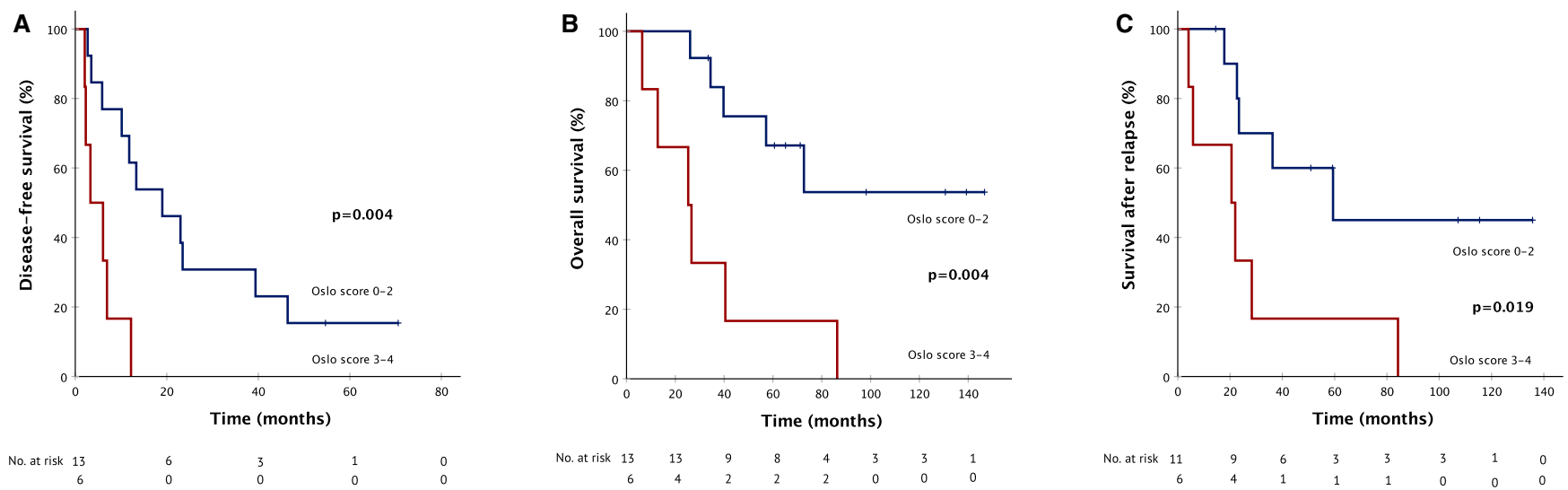

FIGURE 3 Disease-free survival (A), overall survival (B), and survival after relapse (C), from time of liver transplant in patients with colorectal cancer with nonresectable liver-only metastases receiving liver transplant. Blue line, Oslo Score 0 to 2; red line, Oslo Score 3 to 5 [Color figure can be viewed at wileyonlinelibrary.com]

to 2 have been observed for 55 and 71 months without a relapse. These are the same patients as the 2 patients with an FRCS of 0 to 2 without signs of recurrence. The 5 -year OS in patients with an Oslo Score of 0 to 2 was $67 \%$ compared with $17 \%$ in patients with an Oslo Score of 3 to 4 (Figure 3B). The longest OS in patients with an Oslo Score of 3 to 4 was 86 months. In contrast, a patient is alive after 33 months, and 7 of 13 patients with an Oslo Score of 0 to 2 are alive $>60$ months after LT, with 1 patient observed for 147 months posttransplant. No patient with an Oslo score of 4 survived for 5 years. Patients with an Oslo Score of 0 to 2 had 5 -year OS from time of relapse of $45 \%$ compared with $17 \%$ in patients with an Oslo Score of 3 to $4(P=.019$; Figure $3 C)$. One patient with an Oslo Score of 0 to 2 is still alive 136 months after relapse.

Five patients had KRAS mutant and 13 had KRAS wild-type (wt) tumors, whereas KRAS mutation status could not be determined in 1 patient. There was no significant difference in OS between patients with KRAS wt and mutant status (median 73 months vs 40 months, $P=.754$ ).

Four patients had a primary tumor in the ascending colon (rightsided primary tumor) compared with 15 patients with their primary tumor in the transverse colon $(n=1)$, left colon $(n=2)$, sigmoid
( $n=4)$, or rectum ( $n=8$ ) (left-sided primary tumors). Patients with right-sided primary tumor had significantly reduced DFS compared with patients with left-sided tumors, with a median DFS of 4 months and 13 months, respectively ( $P=.044$; Figure $4 A$ ), and OS was 6 to 40 months in the right-sided group. In comparison, patients with leftsided primary had a median OS of 86 months and 5-year OS of $66 \%$ $(P=.001$; Figure 4B). Further, patients with right-sided tumors had shorter OS from time of relapse compared with left-sided tumors ( $P=.016)$, and all patients with right-sided primary tumors were dead at 37 months after the recurrence. In contrast, the median OS from time of relapse in patients with left-sided tumors was 59 months, with 3 patients alive 107 to 136 months after relapse (Figure 4C). There was no significant difference in age, sex, MTV, MTV $<70$ $\mathrm{cm}^{3}$, FCRS, Oslo Score, CEA level, largest liver lesion, and number of liver lesions between right-sided tumors and left-sided tumors. However, right-sided tumors had borderline more KRAS mutated tumors $(P=.079)$ (Table 3 ).

Nine patients had elevated CEA plasma levels at time of LT. They all relapsed within 2 years from LT, whereas 2 patients with normal CEA levels were observed for 55 and 71 months without

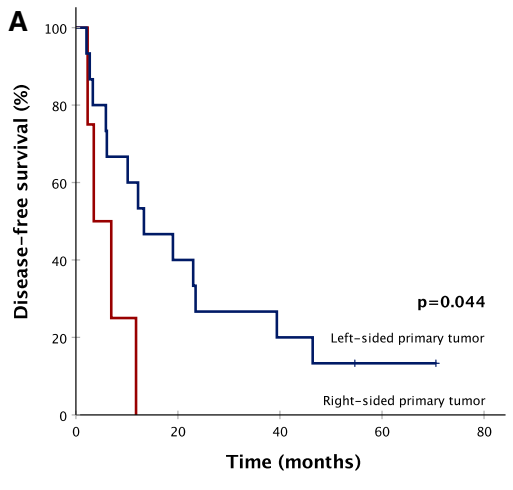

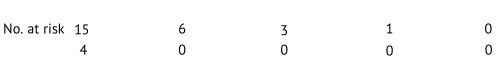

B

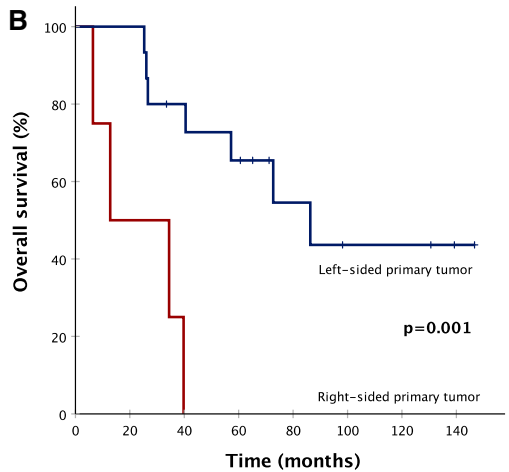

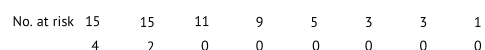

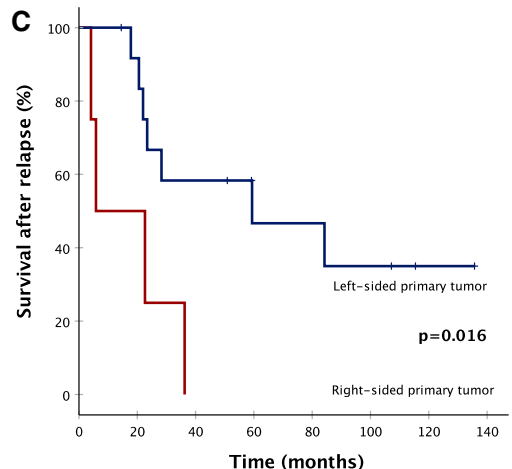

No. at risk $13 \quad \begin{array}{lllllll}11 & 7 & 4 & 4 & 3 & 1 & 0\end{array}$

FIGURE 4 Disease-free survival (A), overall survival (B), and survival after relapse (C), from time of liver transplant in patients with colorectal cancer with nonresectable liver-only metastases receiving liver transplant. Red line, right-sided primary tumor; blue line, left-sided primary tumor [Color figure can be viewed at wileyonlinelibrary.com] 
TABLE 3 Different baseline parameters between right- and leftsided primary tumors at time of transplant (median and range)

\begin{tabular}{|c|c|c|c|}
\hline & $\begin{array}{l}\text { Right-sided } \\
(n=4)\end{array}$ & $\begin{array}{l}\text { Left-sided } \\
(\mathrm{n}=15)\end{array}$ & $P$ value ${ }^{a}$ \\
\hline $\begin{array}{l}\text { Time from primary } \\
\text { surgery to LT (mo) }\end{array}$ & $9(6-29)$ & $23(2-78)$ & .124 \\
\hline Age, y & $49(29-61)$ & $58(45-71)$ & .152 \\
\hline Sex (female/male) & $3 / 1$ & $5 / 10$ & .221 \\
\hline FCRS at LT & $3.5(3-5)$ & $3(1-5)$ & .411 \\
\hline Oslo Score at LT & $2.5(2-4)$ & $1(0-4)$ & .185 \\
\hline No. of lesions & $11(5-35)$ & $7(1-53)$ & .665 \\
\hline Size of lesions (mm) & $75(30-119)$ & $34(7-130)$ & .357 \\
\hline CEA $(\mu \mathrm{g} / \mathrm{L})$ & $140(2-279)$ & $4(1-2002)$ & .530 \\
\hline KRAS (wt/mutant) & $1 / 3$ & $12 / 2$ & .079 \\
\hline (y)pT-stage & $\begin{array}{l}\text { T0 = 1 } \\
\text { T3 = } 3\end{array}$ & $\begin{array}{l}\text { T0 }=1, \\
\text { T2 = 1, } \\
\text { T3 = 13 }\end{array}$ & .736 \\
\hline (y)pN-stage & $\begin{array}{c}\mathrm{N} 0=1 \\
\mathrm{~N} 1=1 \\
\mathrm{~N} 2=2\end{array}$ & $\begin{array}{c}\mathrm{N} 0=8 \\
\mathrm{~N} 1=3 \\
\mathrm{~N} 2=4\end{array}$ & .357 \\
\hline $\operatorname{MTV}\left(\mathrm{cm}^{3}\right)$ & $123(0-874)$ & $23(0-397)$ & .530 \\
\hline $\begin{array}{l}\mathrm{MTV}<70 \mathrm{~cm}^{3} \mathrm{vs}>70 \\
\mathrm{~cm}^{3}\end{array}$ & $1 / 3$ & $9 / 6$ & .307 \\
\hline
\end{tabular}

CEA, carcinoembryonic antigen; FCRS, Fong Clinical Risk Score; LT, liver transplant; MTV; metabolic tumor volume.

${ }^{a}$ Nonparametric Mann-Whitney $U$ test.

recurrence. Median DFS in patients with CEA levels within and beyond the normal range was 12 and 6 months, respectively $(P=.055)$. The 5 -year OS in patients with elevated CEA as opposed to within normal levels was $40 \%$ and $60 \%$, respectively $(P=.150)$. Patients with CEA values in the normal range at time of LT had 5 -year OS after relapse of $50 \%$ compared with $13 \%$ in patients with elevated CEA values $(P=.424)$.

$\mathrm{KM}$-estimated OS and range of OS observed based on the 3 selection criteria (PET MTV values $<70 \mathrm{~cm}^{3}$, FCRS of 0 to 2 , and Oslo Score of 0 to 2) are given in Table 4. An FCRS of 0 to 2 gave the best OS, but a selection based on an FRCS of 0 to 2 would mean that fewer than half of the patients would have been offered a transplant compared with the Oslo criteria of 0 to 2 . The 6 patients with an FRCS of 0 to 2 all had MTV $<70 \mathrm{~cm}^{3}$ and an Oslo Score of 0 to 2, with 3 having an Oslo Score of 0 and 2 having a score of 1 , and the last 1 having an Oslo Score of 2 . The 3 patients with metachronous liver metastases and lymph node-negative primary tumor were in the FCRS 0-to-2 group. These 3 patients are all alive $>10$ years (131 to 147 months) after LT and 107 to 136 months after relapse.

\section{4 | DISCUSSION}

The 5-year OS in patients with a median of 1 resectable CRLM is about $50 \%$ both with and without neo-/adjuvant chemotherapy. ${ }^{4}$ Patients with nonresectable CRLM have a median OS from the start of firstline chemotherapy of about 2 years and 5 -year OS of about $10 \% .^{6-9,16}$ Selective internal radiation therapy in addition to standard chemotherapy did not increase OS in a randomized trial. ${ }^{17}$ Further, patients with intolerance or progressive disease on second or third lines of chemotherapy have a median OS of about 5 to 7 months. The new approved drugs in metastatic CRC-regorafenib and TAS-102-increased OS by 1.4 to 1.8 months compared with best supportive care. ${ }^{18,19}$ In a similar cohort of patients, we have previously shown that LT results in a median OS of 41 months and a 5 -year OS of $44 \%,{ }^{20}$ indicating the superiority of LT compared with oncological treatment. In the present report, a 5 -year OS of up to $100 \%$ in highly selected cases was obtained (6/19 patients). The scarcity of organs mandates selection of the patients who benefit the most from LT. In this report, we present mature longterm data after LT. All the patients still alive were followed for $>5$ years, except 1 patient with a follow-up of 34 months.

The total number and size of the largest lesion are of prognostic importance for outcome in transplant for HCC. Patients within the Milan criteria have in general a 5 -year OS of about $75 \%,{ }^{10}$ whereas increasing the number and size of largest lesion reduces the 5-year OS according to the "metro-ticket" concept. ${ }^{21}$ Recently, biological markers have been added to the metro-ticket concept. Similarly, a scoring system based on morphology of liver lesions and factors like CEA may be used for selecting patients with CRLM for LT to obtain long OS. ${ }^{13,15}$

The majority of the patients experienced a relapse; however, in contrast to $\mathrm{HCC}$ with recurrence, the $\mathrm{CRC}$ cohort had a long OS from the time of relapse, ${ }^{22}$ exceeding 5 years in many cases (Figures $1 \mathrm{C}$, $2 \mathrm{C}$ and $3 \mathrm{C}$ ). The long survival time after relapse might be explained by that the recurrences were mostly slow growing and often resectable pulmonary metastases, thus providing the patients a status of no evidence of disease. ${ }^{23}$

The current report shows that different scoring systems may select patients with CRLMs to obtain long-term OS (Figures 1B,

TAB LE 4 Overall survival after liver transplant based on different selection criteria

\begin{tabular}{|c|c|c|c|c|c|}
\hline Group & No. of patients & $\begin{array}{l}\text { Overall survival } \\
\text { (mo) }\end{array}$ & $\begin{array}{l}\text { Kaplan-Meier } 5-y \\
\text { overall survival (\%) }\end{array}$ & $\begin{array}{l}\text { No. of patients } \\
\text { observed }>5 \mathrm{y}^{\mathrm{a}}\end{array}$ & $\begin{array}{l}\text { No. of patients who } \\
\text { died before } 5 \text { y }\end{array}$ \\
\hline $\mathrm{MTV}<70 \mathrm{~cm}^{3}$ & 10 & $33-147$ & 78 & $7 / 9$ & 2 \\
\hline FCRS 0-2 & 6 & $33-147$ & 100 & $5 / 5$ & 0 \\
\hline Oslo Score 0-2 & 13 & $22-147$ & 67 & $8 / 12$ & 3 \\
\hline
\end{tabular}

FCRS, Fong Clinical Risk Score; MTV; metabolic tumor volume.

${ }^{a}$ One additional patient is alive 33 months after liver transplant. 
2B, and 3B). The tradeoff in applying very stringent criteria is obviously that few patients will be eligible. Low FCRS ( 0 to 2 ) provided the highest 5 -year OS but would limit the cohort to $30 \%$ of the patients. All of the 3 scoring systems separated patients with long vs short OS after relapse, but which selection criterion to use is dependent on what is considered an acceptable survival outcome balanced against waiting times and waitlist mortality in the region. Access to living donation might lead to different considerations. Because recurrence alone is not predictive of short survival, DFS is not an appropriate outcome parameter with which to assess the efficacy of LT in CRLM. ${ }^{22}$

Similar to the experience seen in liver resection ${ }^{24-26}$ and palliative chemotherapy, ${ }^{27}$ right-sided tumors were associated with an inferior outcome, with no patient surviving 5 years. Thus, caution is probably warranted in offering these patients LT (Figure 4B).

Metachronous disease was associated with long OS with 2 patients alive 10.9 to 12.3 years after LT; 1 additional patient died after 7.7 years of a sudden, unrelated cardiovascular event. These findings, although based on small numbers, suggest that patients with metachronous disease have a considerable benefit of LT compared with palliative chemotherapy.

The data presented are mature with median follow-up of 85 months. The majority of low-risk patients are alive, and median OS in these groups will increase even further. Using the presented scoring systems and considering clinical parameters like metachronous disease and location of the primary tumor, a selection ensuring an OS comparable to standard indications for LT is possible. Based on the 3 scoring systems, 0.24 to 0.51 patient per 1 million people per year would be eligible, representing $1 \%$ to $2 \%$ of yearly transplants in United States. A consequence of the present results suggests that highly selected patients with CRC may be considered for LT as part of prospective studies because the total world experience is still limited.

\section{DISCLOSURE}

The authors of this manuscript have no conflicts of interest to disclose as described by the American Journal of Transplantation.

\section{ORCID}

Svein Dueland (iD https://orcid.org/0000-0002-6125-6689

Harald Grut iD https://orcid.org/0000-0001-9271-8789

\section{DATA AVAILABILITY STATEMENT}

This was a retrospective analysis of data from the prospective SECA-I ${ }^{12}$ and SECA-II ${ }^{13}$ studies.

\section{REFERENCES}

1. Ferlay J, Soerjomataram I, Dikshit R, et al. Cancer incidence and mortality worldwide: sources, methods and major patterns in GLOBOCAN 2012. Int J Cancer. 2015;136(5):E359-E386.

2. Fong $\mathrm{Y}$, Fortner J, Sun RL, Brennan MF, Blumgart LH, Blumgart LH. Clinical score for predicting recurrence after hepatic resection for metastatic colorectal cancer: analysis of 1001 consecutive cases. Ann Surg. 1999;230(3):18-21; discussion 18-21.
3. Quan D, Gallinger S, Nhan C, et al. The role of liver resection for colorectal cancer metastases in an era of multimodality treatment: a systematic review. Surgery. 2012;151(6):860-870.

4. Nordlinger B, Sorbye H, Glimelius B, et al. Perioperative FOLFOX4 chemotherapy and surgery versus surgery alone for resectable liver metastases from colorectal cancer (EORTC 40983): long-term results of a randomised, controlled, phase 3 trial. Lancet Oncol. 2013;14(12):1208-1215.

5. Boeckx N, Koukakis R, Op de Beeck K, et al. Primary tumor sidedness has an impact on prognosis and treatment outcome in metastatic colorectal cancer: results from two randomized first-line panitumumab studies. Ann Oncol. 2017;28(8):1862-1868.

6. Douillard J-Y, Siena S, Cassidy J, et al. Randomized, phase III trial of panitumumab with infusional fluorouracil, leucovorin, and oxaliplatin (FOLFOX4) versus FOLFOX4 alone as first-line treatment in patients with previously untreated metastatic colorectal cancer: the PRIME study. J Clin Oncol. 2010;28(31):4697-4705.

7. Dueland S, Guren TK, Hagness M, et al. Chemotherapy or liver transplantation for nonresectable liver metastases from colorectal cancer? Ann Surg. 2015;261(5):956-960.

8. Giantonio BJ, Catalano PJ, Meropol NJ, et al. Bevacizumab in combination with oxaliplatin, fluorouracil, and leucovorin (FOLFOX4) for previously treated metastatic colorectal cancer: results from the Eastern Cooperative Oncology Group Study E3200. J Clin Oncol. 2007;25(12):1539-1544.

9. Masi G, Vasile E, Loupakis F, et al. Randomized trial of two induction chemotherapy regimens in metastatic colorectal cancer: an updated analysis. J Natl Cancer Inst. 2011;103(1): 21-30.

10. Mazzaferro V, Regalia E, Doci R, et al. Liver transplantation for the treatment of small hepatocellular carcinomas in patients with cirrhosis. N Engl J Med. 1996;334(11):693-699.

11. Le Treut YP, Grégoire E, Klempnauer J, et al. Liver transplantation for neuroendocrine tumors in Europe-results and trends in patient selection: a 213-case European liver transplant registry study. Ann Surg. 2013;257(5):807-815.

12. Muhlbacher F, Huk I, Steininger R, et al. Is orthotopic liver transplantation a feasible treatment for secondary cancer of the liver? Transpl Proc. 1991;23(1 Pt 2):1567-1568.

13. Hagness M, Foss A, Line P-D, et al. Liver transplantation for nonresectable liver metastases from colorectal cancer. Ann Surg. 2013;257(5):800-806.

14. Grut H, Dueland S, Line PD, Revheim ME. The prognostic value of (18)F-FDG PET/CT prior to liver transplantation for nonresectable colorectal liver metastases. Eur J Nucl Med Mol Imaging. 2018; 45(2):218-225.

15. Dueland S, Syversveen T, Solheim JM, et al. Survival following liver transplantation for patients with non-resectable liver only colorectal metastases. Ann Surg. 2019. https://doi.org/10.1097/ SLA.0000000000003404.

16. Van Cutsem E, Kohne $\mathrm{CH}$, Lang I, et al. Cetuximab plus irinotecan, fluorouracil, and leucovorin as first-line treatment for metastatic colorectal cancer: updated analysis of overall survival according to tumor KRAS and BRAF mutation status. J Clin Oncol. 2011;29(15):2011-2019.

17. Wasan HS, Gibbs P, Sharma NK, et al. First-line selective internal radiotherapy plus chemotherapy versus chemotherapy alone in patients with liver metastases from colorectal cancer (FOXFIRE, SIRFLOX, and FOXFIRE-Global): a combined analysis of three multicentre, randomised, phase 3 trials. Lancet Oncol. 2017;18(9):1159-1171.

18. Grothey A, Cutsem EV, Sobrero A, et al. Regorafenib monotherapy for previously treated metastatic colorectal cancer (CORRECT): an international, multicentre, randomised, placebo-controlled, phase 3 trial. Lancet. 2013;381(9863):303-312. 
19. Mayer RJ, Van Cutsem E, Falcone A, et al. Randomized trial of TAS-102 for refractory metastatic colorectal cancer. N Engl J Med. 2015;372(20):1909-1919.

20. Dueland S, Hagness M, Line PD, Guren TK, Tveit KM, Foss A. Is liver transplantation an option in colorectal cancer patients with nonresectable liver metastases and progression on all lines of standard chemotherapy? Ann Surg Oncol. 2015;22(7):2195-2200.

21. Mazzaferro V, Llovet JM, Miceli R, et al. Predicting survival after liver transplantation in patients with hepatocellular carcinoma beyond the Milan criteria: a retrospective, exploratory analysis. Lancet Oncol. 2009;10(1):35-43.

22. Dueland S, Foss A, Solheim JM, Hagness M, Line PD. Survival following liver transplantation for liver-only colorectal metastases compared with hepatocellular carcinoma. Br J Surg. 2018;105:736-742.

23. Grut $\mathrm{H}$, Solberg S, Seierstad T, et al. Growth rates of pulmonary metastases after liver transplantation for unresectable colorectal liver metastases. Br J Surg. 2018;105(3):295-301.

24. Sasaki K, Margonis GA, Wilson A, et al. Prognostic implication of KRAS status after hepatectomy for colorectal liver metastases varies according to primary colorectal tumor location. Ann Surg Oncol. 2016;23(11):3736-3743.
25. Wang K, Xu D, Yan XL, Poston G, Xing BC. The impact of primary tumour location in patients undergoing hepatic resection for colorectal liver metastasis. Eur J Surg Oncol. 2018;44(6): 771-777.

26. Creasy JM, Sadot E, Koerkamp BG, et al. The impact of primary tumor location on long-term survival in patients undergoing hepatic resection for metastatic colon cancer. Ann Surg Oncol. 2018;25(2):431-438.

27. Cremolini C, Antoniotti C, Lonardi S, et al. Primary tumor sidedness and benefit from FOLFOXIRI plus bevacizumab as initial therapy for metastatic colorectal cancer. Ann Oncol. 2018;29:1528-1534.

How to cite this article: Dueland S, Grut H, Syversveen T, Hagness M, Line P-D. Selection criteria related to long-term survival following liver transplantation for colorectal liver metastasis. Am J Transplant. 2020;20:530-537. https://doi. org/10.1111/ajt.15682 